\title{
The usefulness and limitations of diffusion tensor imaging - a review study
}

\author{
Sara Kierońska ${ }^{1,2}$ ๑ , Paweł Słoniewski² $\odot$ \\ ${ }^{1}$ Jan Biziel University Hospital Collegium Medicum Nicolaus Copernicus University, \\ Department of Neurosurgery and Neurology, Bydgoszcz, Poland \\ ${ }^{2}$ Department of Neurosurgery, Medical University of Gdańsk, Poland
}

\begin{abstract}
Diffusion tensor tractography (DTI) has been used for planning of a brain pathology surgeries. Knowledge about the distances between neural tracts and brain tumours is believed to increase the patient safety and implies the extent of resection. The aim of the study was to demonstrate the contemporary possibilities and the clinical usefulness of DTI. Following the explanation of the technical basics of DTI, we presented the drawbacks and limitations of this visualisation technique. The most commonly outlined tracts are corticospinal tract (CST), arcuate fasciculus (AF) and frontal aslant tract (FAT). Tumour located in frontal, parietal or temporal lobe can affect the course of the CST. There are two basic possibilities to visualise CST: deterministic and probabilistic. The usefulness of DTI seems limited in imaging the neoplasms of either frontal or temporal region causing aphasia, which infiltrate the AF or the FAT. This limitation is probably related to divergent and patient-specific location of functional speech areas. Acquisition disturbances, ill-defined mathematical algorithms, surgery-related brain shift and defining wrong non-functional brain area are the sources of DTI inaccuracy, which is limiting its clinical application.
\end{abstract}

Keywords: Diffusion Tensor Imaging · tractography · corticospinal tract • arcuate fasciculus · frontal aslant tract

\section{Citation}

Kierońska S, Słoniewski P. The usefulness and limitations of diffusion tensor imaging - a review study.

Eur J TransI Clin Med. 2019;2(2):43-51.

DOI: $10.31373 /$ ejtcm/112437

\section{Introduction}

Tractography is a non-invasive method of visualizing the white matter of central nervous system (CNS) structures in vivo. It is possible to determine the direction and continuity of neural fibres in either
CNS or peripheral nervous system by using diffusion tensor imaging (DTI), a specific sequence of magnetic resonance (MR) [1]. Tractography allows reconstructing the neural fibres in colourful projections that run simultaneously through particular anatomical regions of the brain. Important neural pathways are tracked

Corresponding author:

Sara Kierońska, Jan Biziel University Hospital Collegium Medicum Nicolaus Copernicus University, Department of Neurosurgery and Neurology, Bydgoszcz, Poland e-mail: sara.kieronska@gmail.com

No external funds.

Available online: www.eitcm.gumed.edu.pl

Copyright ${ }^{\circledR}$ Medical University of Gdańsk

This is Open Access article distributed under the terms of the Creative Commons Attribution-ShareAlike 4.0 International. 
by utilising the connection map and their course correlates with some pathological changes in the CNS [2-3]. That information is essential in neurosurgeon's preoperative planning, as it leads to an improvement in setting boundaries for tumour resection and decrease of post-surgery neurological deficits.

Tractography utilises the data provided by the MR tensor, which returns information about size and the direction of the diffusion. The sketch of the white matter pathways through the selected anatomical points is based on the principles of voxel continuity [4]. There are several analytical methods used in the assessment of anatomical differences between specific groups of patients. Nevertheless, the most commonly used is the voxel-based analysis. It is easily adjustable to the needs of the neurosurgeon and makes it possible to assess the degree of tissue diffusion simultaneously throughout the encephalon, which points out the possible locations of tumour infiltrations. Another widely used method is an analysis of the region of interest (ROI) which enables the precise assessment of the degree of diffusion in hypothetically determined locations [5-6].

Studies conducted on neurosurgical patients revealed that total or subtotal brain tumor resection leads to improved survival. The specific success rate is directly connected with a lower risk of tumour relapse [7-8]. From the patient's perspective, it is crucial to maintain quality of life, motor function and speech after undergoing surgery [9]. The vast majority of available literature refers to the preclinical technical aspects of DTI and rarely describes its practical application. Currently, only several of these practical possibilities that DTI gives are utilised in modern neurosurgery. These need to be summarised in a comprehensive review, which is not only directed at neurosurgeons but also radiologists and neurologists. In this study, we reviewed not only the usefulness but also the potential limitations of DTI in brain tumour surgery.

\section{Tractography}

Tractography is a method of spatial imaging of computational radiological data. It allows various neural fibres to be tracked, which is a result of different diffusion of a single voxel. Many professional applications, both paid and freeware, are used for tracking, fusing of the sequences and comparative analyses. These are widely available and have great flexibility in the data processing. Images can be saved in a variety of formats, printed and transferred to operating rooms or used for research purposes. The most clinically valid and nonetheless spectacular graphic presentation of DTI is a directionally encoded colour (DEC) sequence. DEC is conditioned by the direction of the diffusion vector of white matter. According to built-in, automatic, anatomical atlases, applications allow precise determination of neural structures and some of the main fibre pathways. These structures are named regions of interest (ROIs). By setting one or more ROI, the application automatically calculates and draws white matter fibres. To note, visualising an individual neural pathway is also possible. The software also allows sketching the location of the tumour concerning the previously designated path.

At our department, we performed DTI for all patients with suspected tumour infiltration, according to internal DTI protocol, resulting in a total of 60 diffusion sampling directions acquired. Parameters of those MRI examinations were as follows:

- b-value: $1000 \mathrm{~s} / \mathrm{mm} 2$,

- in-plane resolution: $1.95313 \mathrm{~mm}$,

- thickness: $2 \mathrm{~mm}$,

- angular threshold: $90^{\circ}$.

The obtained pattern of neaural tracts, as well as the outlined tumour, can be imported into the neuronavigation system, which seems to be the leading, practical advantage of all DTI methods.

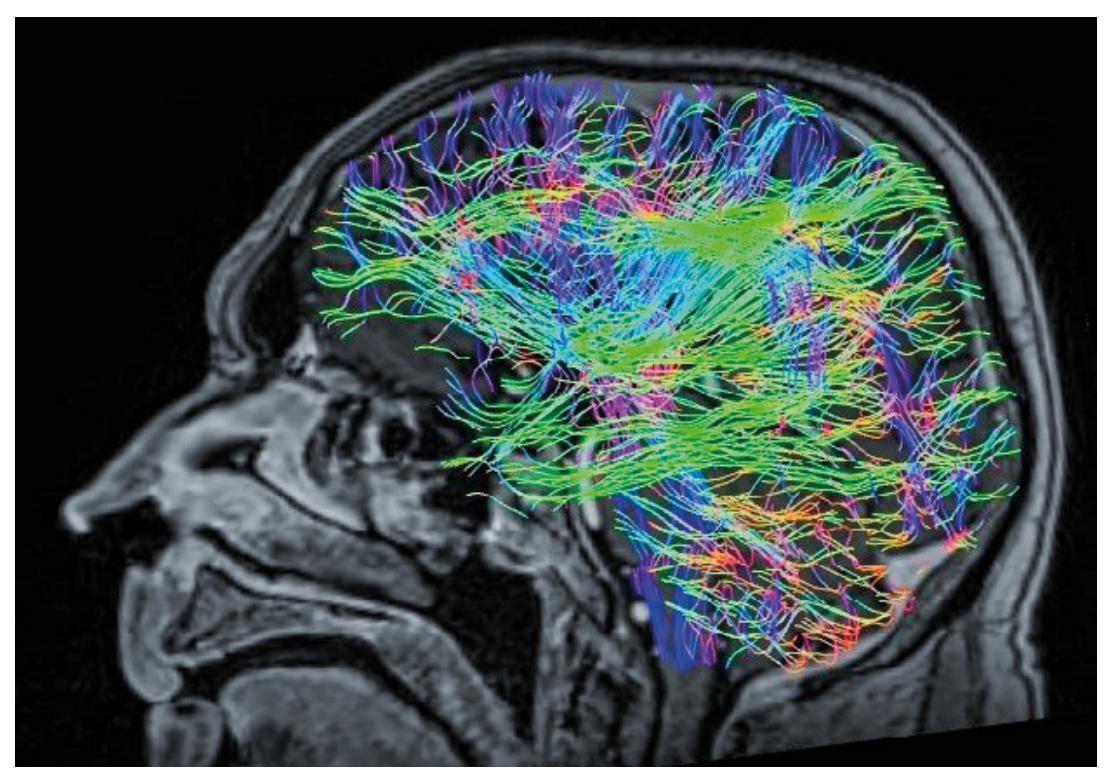

Figure 1. Directionally encoded colour (DEC) sequence of the diffusion tensor tractography depicts the course of white matter fibres. In standard markings, the red colour means left-right, green front-back and blue top-to-bottom directions of white matter fibres 
There are two basic techniques for creating models of neural pathways: probabilistic and deterministic. The deterministic approach implies drawing the fibres in the system by marking one starting point and another ROI. Utilising this technique, the defined neural bundle assumes only one direction assigned to the single voxel. Therefore, the main limitation of this approach is the high anatomical variability of neural pathways and the fact that some of the fibres intersect each other [10]. Table 1 presents selected articles comparing both methods.

Table 1. Comparison of methods of tractography: the probabilistic and deterministic. The practical application of each technique was extracted from the studies

\begin{tabular}{|c|c|c|c|c|c|}
\hline Author & Title & Year & Tract & $\begin{array}{c}\text { Probabilistic } \\
\text { vs. } \\
\text { Deterministic }\end{array}$ & Clinical impact \\
\hline $\begin{array}{c}\text { Zolal A et al. } \\
{[1]}\end{array}$ & $\begin{array}{c}\text { Comparison } \\
\text { of probabilistic } \\
\text { and deterministic fibre } \\
\text { tracking of cranial nerves }\end{array}$ & 2017 & $\begin{array}{l}\text { Cranial } \\
\text { nerves: } \\
\text { II, III,V, } \\
\text { VII,VIII }\end{array}$ & Probabilistic & $\begin{array}{l}\text { Probabilistic tracking } \\
\text { is more effective } \\
\text { than the previously } \\
\text { described deterministic }\end{array}$ \\
\hline $\begin{array}{l}\text { Schlaier JR } \\
\text { et al. [2] }\end{array}$ & $\begin{array}{l}\text { Probabilistic vs. deterministic } \\
\text { fibre tracking and the } \\
\text { influence of different seed } \\
\text { regions to delineate } \\
\text { cerebellar-thalamic fibers } \\
\text { in deep brain stimulation }\end{array}$ & 2017 & $\begin{array}{l}\text { Dentate-rubro } \\
\text { thalamic tract }\end{array}$ & Probabilistic & $\begin{array}{l}\text { Probabilistic fibre tracking was } \\
\text { more sensitive and provides } \\
\text { more accurate tracking solutions } \\
\text { for dentate-rubro-thalamic tract }\end{array}$ \\
\hline $\begin{array}{c}\text { Jenabi } M \text { et al. } \\
\text { [3] }\end{array}$ & $\begin{array}{l}\text { Identification of the } \\
\text { Corticobulbar Tracts of the } \\
\text { Tongue and Face Using } \\
\text { Deterministic and Probabilistic } \\
\text { DTI Fibre Tracking in } \\
\text { Patients with Brain Tumor }\end{array}$ & 2015 & $\begin{array}{c}\text { Corticobulbar } \\
\text { tract }\end{array}$ & Probabilistic & $\begin{array}{l}\text { Probabilistic tractography } \\
\text { successfully reconstructs the } \\
\text { face- and tongue-associated } \\
\text { corticobulbar tracts from the } \\
\text { lateral primary motor cortex to } \\
\text { the pons in both hemispheres }\end{array}$ \\
\hline $\begin{array}{c}\text { Jenabi } M \text { et al. } \\
{[4]}\end{array}$ & $\begin{array}{l}\text { Probabilistic fibre tracking } \\
\text { of the language and motor } \\
\text { white matter pathways of } \\
\text { the supplementary motor } \\
\text { area (SMA) in patients with } \\
\text { brain tumors }\end{array}$ & 2014 & $\begin{array}{l}\text { Broca's } \\
\text { area } \\
\text { to SMA }\end{array}$ & Probabilistic & $\begin{array}{l}\text { The identification of unique } \\
\text { areas of white matter } \\
\text { according to the probabilistic } \\
\text { method allows the location } \\
\text { of the tract connecting } \\
\text { Broca's area to SMA }\end{array}$ \\
\hline $\begin{array}{l}\text { Li Z } \\
\text { et al. [5] }\end{array}$ & $\begin{array}{l}\text { Diffusion tensor } \\
\text { tractography of the arcuate } \\
\text { fasciculus in patients with } \\
\text { brain tumors: Comparison } \\
\text { between deterministic and } \\
\text { probabilistic models }\end{array}$ & 2013 & $\begin{array}{c}\text { Arcuate } \\
\text { fasciculus }\end{array}$ & Probabilistic & $\begin{array}{l}\text { Probabilistic tractography } \\
\text { reconstructs the arcuate } \\
\text { fasciculus more completely } \\
\text { and performs better } \\
\text { through areas of tumor } \\
\text { and/or edema }\end{array}$ \\
\hline
\end{tabular}




\begin{tabular}{|c|c|c|c|c|c|}
\hline $\begin{array}{l}\text { Burkett D] } \\
\text { et al. [6] }\end{array}$ & $\begin{array}{l}\text { Deterministic } \\
\text { Tractography } \\
\text { of the Descending } \\
\text { Tract of the Spinal } \\
\text { Trigeminal Nerve } \\
\text { Using Diffusion } \\
\text { Tensor Imaging }\end{array}$ & 2017 & $\begin{array}{l}\text { descending } \\
\text { tract } \\
\text { of the } \\
\text { trigeminal } \\
\text { nerve }\end{array}$ & Determinitsic & $\begin{array}{l}\text { The identification of unique } \\
\text { areas of white matter } \\
\text { according to the probabilistic } \\
\text { method allows the location } \\
\text { of the tract connecting } \\
\text { Broca's area to SMA }\end{array}$ \\
\hline $\begin{array}{l}\text { Anthofer JM } \\
\text { et al. [7] }\end{array}$ & $\begin{array}{l}\text { DTI-based } \\
\text { deterministic } \\
\text { fibre tracking } \\
\text { of the medial } \\
\text { forebrain bundle }\end{array}$ & 2015 & $\begin{array}{l}\text { medial } \\
\text { forebrain } \\
\text { bundle }\end{array}$ & Determinitsic & $\begin{array}{l}\text { Deterministic tractography } \\
\text { with different ROIs } \\
\text { provides variable } \\
\text { delineations of the course } \\
\text { of the medial } \\
\text { forebrain bundle }\end{array}$ \\
\hline
\end{tabular}

Most authors use a probabilistic method for ascertaining a specific tract. The obtained images of DTI are easy to interpret for most of them [17-18]. The advantage of probabilistic tractography is an obtained sketch of neural tracts that presents any structural changes of white matter adjacent to pathological changes [18]. On the other hand, the deterministic method, is mostly used for the analysis of the course of fibres that have their ending in the voxels with the lowest FA value [10]. For the clinical purpose, the deterministic model is chosen less frequently, although it has some clinical advantages. In our experience, the deterministic approach results in better visualisation of the corticospinal tract (CST) adhering to tumours of the medial frontal lobe.

There are over 50 patients who had deterministic tracking of the CST before undergoing surgery at the Neurosurgery Department of the Medical University of Gdańsk (Poland). Those surgeries confirmed the position of CST with the clinical findings. Other studies confirm our observations [19].

\section{Clinical application of tractography}

The precise visualisation of the neural pathways and their topographic relation to the tumour increases the safety of the surgery, even though DTI fibres are not the same as the actual neural pathways [19-20]. Optimal preoperative planning allows the operating team to minimise the potential damage of vital white matter during the surgery [21-22]. The images created during the preoperative planning can be superimposed in realtime onto the view shown in the operative microscope. This way the neurosurgeon can remove the tumour relying solely on the preoperative planning in what is known as 'image-guided surgery' [23].

\section{Corticospinal tract}

The CST is the main neuronal route responsible for motor functions of the face, limbs and trunk. CST is composed of descending fibres starting in the pre-centre bend (4th Brodmann area) which transmits neural impulses through the pyramid up to the spinal cord [24]. Infiltration or destruction of CST caused by a brain tumour, ischemic stroke or subarachnoid haemorrhage affects the density of the fibres. Sterr et al demonstrated that the degree of the damage to the pyramidal pathway is closely related to subsequent motor deficits in patients after ischemic stroke [25]. The anatomy of the CST and its topography in relation to the tumour is essential when those two are close to each other [26]. Based on tractographic parameters, we can estimate the degree of CST injury and predict the postoperative neurological outcome [26]. The CST is the neural bundle most commonly tracked by neurosurgeons, including at our centre [27]. Various ROIs can be used to track CST, resulting in high variability rate. Weiss et al showed that an ROI set at the anterior inferior pontine region yielded better tracking results compared to the ROI set at the internal capsule [28-30]. Furthermore, CST was reconstructed from neural bundles passing through by cerebral peduncle, posterior limb of internal capsule and corona radiata in a patient after stroke [31]. This study confirmed the significance of a hind limb of the internal capsule as an ROI for CST 


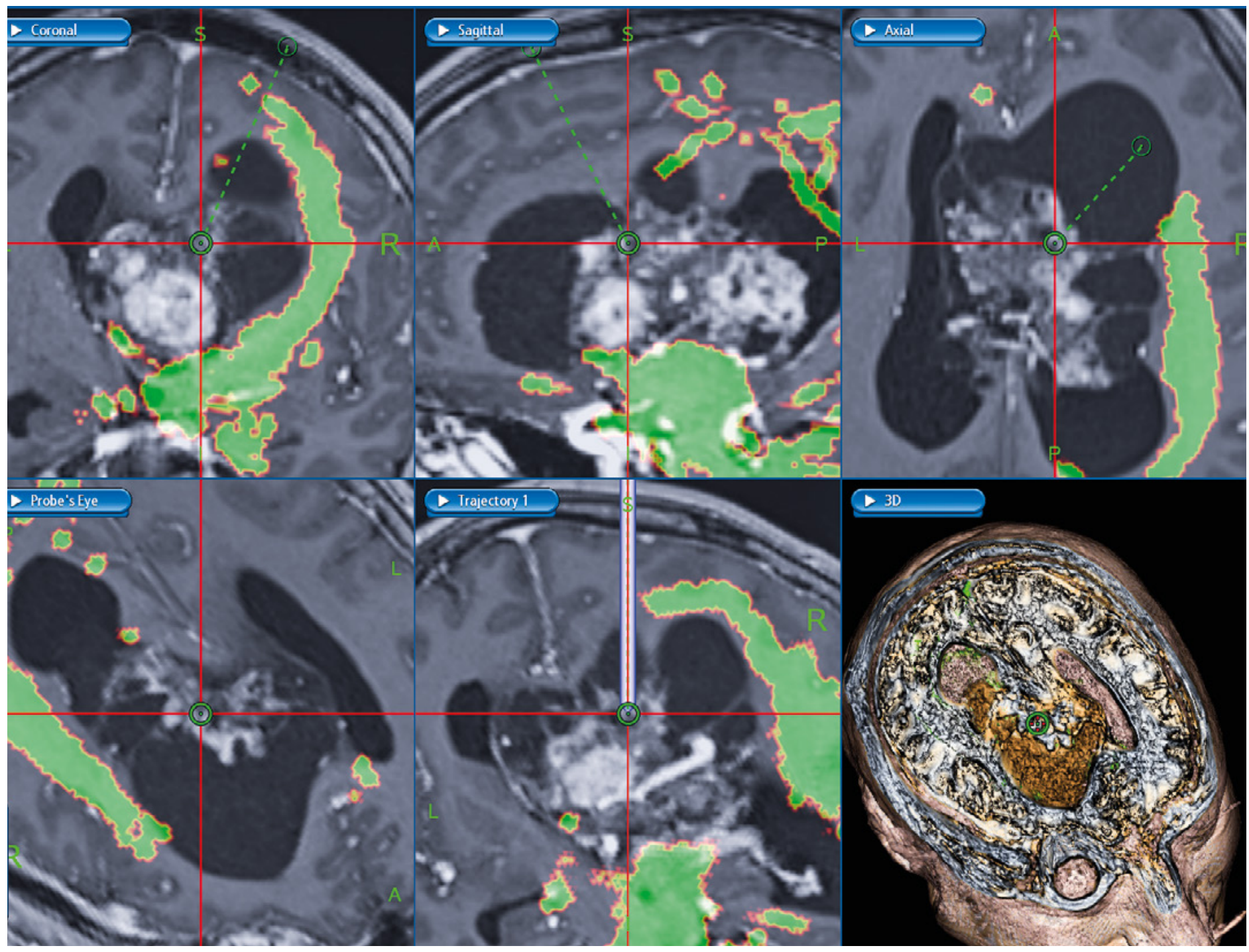

Figure 2. Planning of the surgical approach with the visualisation of the corticospinal tract of a patient with ventricular neurocytoma

tractography. Based on the above suggestions, our department has commenced the DTI analysis comparing the differences between CSTs with various
ROIs. In our experience, we defined two main types of the anatomical ROIs (the cerebral peduncle and posterior limb of the internal capsule) and four additional endpoints:

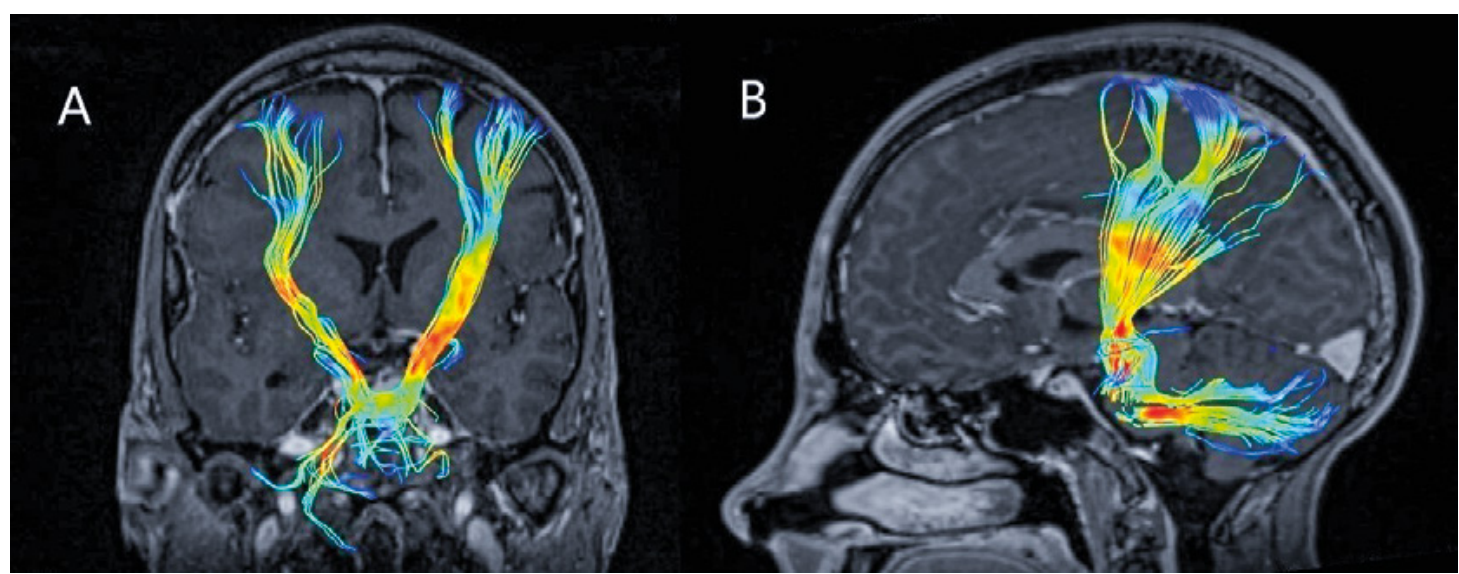
precentral gyrus, postcentral gyrus, supplementary motor a rea and frontal lobe.

Figure 3. Corticospinal tract on preoperative tractography on coronal (A) and sagittal (B) planes 


\section{Arcuate Fasciculus (AF)}

AF is the white matter pathway connecting the Broca speech centre (located in the frontal lobe) with the Wernicke speech centre (temporal lobe). CNS lesions infiltrating AF affect speech because the communication between the Broca and Wernicke areas becomes severed. The patient usually presents with so-called conduction aphasia [32-33]. DTI-based visualisation of AF is an widely accepted management for tumours of eloquent areas. The synchronisation of the tractography with the navigation system determines the precise location of the AF. Therefore, DTI sets boundaries for resection of a tumour located near AF and helps to prevent iatrogenic injury of the speech centre [34]. However, AF alone tractography could not always prevent postoperative aphasia. Cortical mapping, together with neurophysiological monitoring, could be applied for some more demanding tumours, although some surgeons prefer awake craniotomy [35]. Awake craniotomy also improves patient safety in terms of preserving speech functions [36]. The different location of both Broca and Wernicke area among individuals preclude the correct prediction of functionally active $A F$ in DTI, what seems to be the main drawback of DTI tracking of AF, also confirmed by our experience.

Nevertheless, functional MRI also can unambiguously estimate the exact location of speech areas. Researchers should put more effort into studying DTI in terms of speech preservation as awake craniotomy resection is still more reliable in this case [37].

\section{Frontal aslant tract}

The frontal aslant tract (FAT), first described in DTI by Catani et al, contains neural fibres connecting the lower frontal bend (pars triangularis and pars opercularis of the operculum) with the supplementary motor area (SMA) and pre-SMA [38]. Tumors infiltrating SMA or pre-SMA may impede some motor functions, learning and aphasia. In a majority of patients, the FAT projected to the opercularis part of inferior frontal gyrus (IFG) and a greater number of fibres terminated at the triangularis part of IFG in left-handed patients [39]. The course of FAT through the inferior frontal lobe and the Broca's area suggests its significant role in the proper functioning of speech. Patients with progressive aphasia with a significant change within the FAT show particularly large changes in the correlation with AF [38-40]. In studies of the surgical treatment of patients with brain tumours, FAT lesions are associated with transient speech disorders and the occurrence of mutism and motor aphasia $[34,41]$. The accurate prediction of the FAT location is possible thanks to the neuromonitoring techniques and direct stimulation of the cerebral cortex. In one study, the intraoperative stimulation of the left hemisphere FAT during craniotomy caused transient speech disorder of the stuttering type $[34,42]$.

In clinical practice, FAT could be determined to be a means of DTI in patients for whom an awake craniotomy is planned [43]. Baker et al. suggested that FAT and "crossed FAT" are of great importance for tumours infiltrating SMA and pre-SMA $[37,44]$.

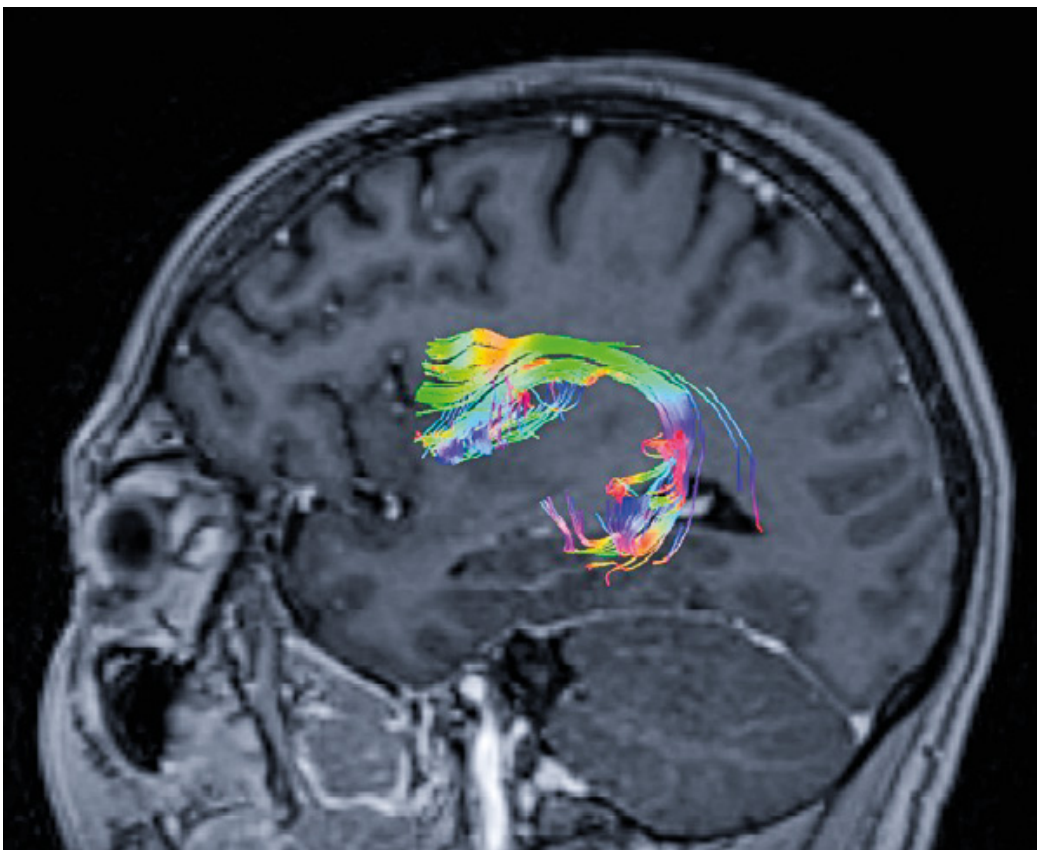

Limitations and future of tractograph

DTI is an imaging method used as a radiological tool for years. However, only the recent development of visualisation of neural tracts, tractography, makes it possible to use on personal computers. Frequent use of tractography leads to the constant improvement of reconstruction methods and these directly influenced the precision of treatment in the clinical setting. The correlation of DTI with a patient's neurological condition is sufficient for an adequate therapeutic process

Figure 4. Arcuate Fasciculus connecting Broca's and Wernicke's areas 


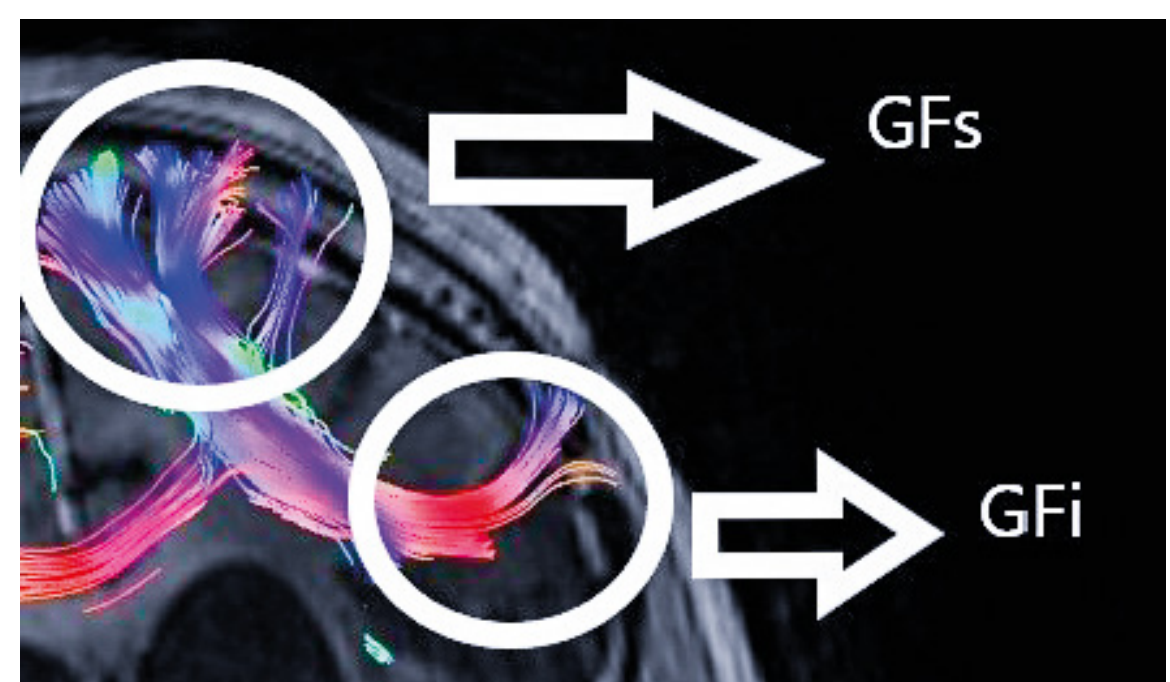

Figure 5. Frontal aslant tract based on two regions of interest--gyrus frontalis superior (GFs) and gyrus frontalis inferior (GFi). Abbreviations: GFs - gyrus frontalis superior, GFi - gyrus frontalis inferior

amount of fibres is damaged during the surgery, it does not necessarily lead to noticeable neurological deficits [21]. It seems that the future of neural tract tracking lies in the development of a universal mathematical model for precise delineation of anatomic-functional structures [23].

Tractography, as a method of imaging, has been used for several years. We've been using it at out department since 2010. In most cases, acquisition parameters are the same but

[45-47]. However, tractography is not considered as a standard approach due to its limitations, variability of obtained data and lack of standardisation of image acquisition parameters.

As mentioned earlier, tractography is a method of spatial imaging of computational radiological data and because of that use of DTI in surgical planning remains virtual. For patients with malignant tumours or significant brain edema, the identification of neural pathways is inaccurate [47]. Furthermore, in the case of sizable cerebrospinal fluid flow, there is a risk of motion artefacts occurring during the DTI acquisition. This functional limitation substantially affects the precision of tractography. For these reasons, DTI techniques should be regarded as complementary in surgical planning or as an educational tool [48].

On the other hand, DTI is still dynamically evolving. Thanks to its widespread use by neurosurgeons, we need continuous research to discover new clinical uses and possibilities of DTI. The main contemporary issue is to find the functional significance of each visualised neural tract. On the contrary, even if a particular ways of determining the nerve path of our patients are based on the experience of the researcher currently responsible for the patient. Nevertheless, conclusions of all the researchers are in line with each other. Also other review articles coincide with our observations about the utility and reliability of the tractography as a standard diagnostic procedure. Furthermore, our results are in line with the experiences published by other teams about the necessity of using the tractography as an essential tool in treatment in patients with a brain tumour.

\section{Conclusions}

DTI is a clinically significant tool in the daily neurosurgical practice. In the current review, we provide examples where tractography is a valuable imaging adjunct. Owing to the limitations of DTI, combining tractography with intraoperative monitoring would allow more accurate preoperative planning and then increase the safety of the surgery. Further standardisation of DTI protocols is needed.

\section{References}

1. Basser PJ, Pajevic S, Pierpaoli C, Duda J, Aldroubi A. In vivo fiber tractography using DT-MRI data. Magn Reson Med [Internet]. 2000;44(4):625-32. Available from: http://www.ncbi.nlm.nih.gov/pubmed/11025519

2. Catani M. Occipito-temporal connections in the human brain. Brain [Internet]. 2003 Sep 1;126(9):2093-107. Available from: https://academic.oup.com/brain/article-lookup/doi/10.1093/brain/awg203

3. Gierek T, Paluch J, Pencak P, Kaźmierczak B, Klimczak-Gołab L. [Magnetic resonance tractography in neuroradiological diagnostic aspects]. Otolaryngol Pol = Polish Otolaryngol [Internet]. 2009;63(5):403-6. Available from: http://linkinghub. elsevier.com/retrieve/pii/S0030665709701519 
4. Radek M, Wiśniewski K, Grochal M, Jastrzębski K, Gębski P, Snopkowska-Wiaderna D, et al. Traktografia rdzenia jako metoda diagnostyczna w trudnych przypadkach guzów śródrdzeniowych. Neurol Neurochir Pol [Internet]. 2013;47(1):74-9. Available from: https://linkinghub.elsevier.com/retrieve/pii/S0028384314602747

5. Gawłowska-Sawosz M, Pawełczyk A, Gębski P, Pawełczyk T, Strzelecki D, Rabe-Jabłońska J. Evaluation of white matter structure changes, as assessed in tractography, and cognitive dysfunctions in patients with early onset schizophrenia and their first-degree relatives. Psychiatr Pol [Internet]. 2017;51(4):735-50. Available from: http://psychiatriapolska.pl/735750

6. Shizukuishi T, Abe O, Aoki S. Diffusion tensor imaging analysis for psychiatric disorders. Magn Reson Med Sci [Internet]. 2013;12(3):153-9. Available from: http://www.ncbi.nlm.nih.gov/pubmed/23857149

7. Smith JS, Chang EF, Lamborn KR, Chang SM, Prados MD, Cha S, et al. Role of Extent of Resection in the Long-Term Outcome of Low-Grade Hemispheric Gliomas. J Clin Oncol [Internet]. 2008 Mar 10;26(8):1338-45. Available from: http:// ascopubs.org/doi/10.1200/JCO.2007.13.9337

8. Dubey A, Kataria R, Sinha V. Role of diffusion tensor imaging in brain tumor surgery. Asian J Neurosurg [Internet]. 2018;13(2):302. Available from: http://www.asianins.org/text.asp?2018/13/2/302/228537

9. Ulmer JL, Salvan C V., Mueller WM, Krouwer HG, Stroe GO, Aralasmak A, et al. The role of diffusion tensor imaging in establishing the proximity of tumor borders to functional brain systems: Implications for preoperative risk assessments and postoperative outcomes. Technol Cancer Res Treat [Internet]. 2004;3(6):567-76. Available from: https://journals. sagepub.com/doi/abs/10.1177/153303460400300606

10. Klein J, Grötsch A, Betz D, Barbieri S, Friman O, Stieltjes B, et al. Qualitative and quantitative analysis of probabilistic and deterministic fiber tracking. In: Dawant BM, Haynor DR, editors. Medical Imaging 2010: Image Processing [Internet]. 2010. p. 76232A. Available from: http://proceedings.spiedigitallibrary.org/proceeding.aspx?doi=10.1117/12.843472

11. Zolal A, Sobottka SB, Podlesek D, Linn J, Rieger B, Juratli TA, et al. Comparison of probabilistic and deterministic fiber tracking of cranial nerves. J Neurosurg [Internet]. 2017;127(3):613-21. Available from: https://thejns.org/view/journals/i-neurosurg/127/3/article-p613.xml

12. Schlaier JR, Beer AL, Faltermeier R, Fellner C, Steib K, Lange M, et al. Probabilistic vs. deterministic fiber tracking and the influence of different seed regions to delineate cerebellar-thalamic fibers in deep brain stimulation. Roeper J, editor. Eur J Neurosci [Internet]. 2017;45(12):1623-33. Available from: https://doi.org/10.1111/ejn.13575

13. Jenabi M, Peck KK, Young RJ, Brennan N, Holodny Al. Identification of the Corticobulbar Tracts of the Tongue and Face Using Deterministic and Probabilistic DTI Fiber Tracking in Patients with Brain Tumor. Am J Neuroradiol [Internet]. 2015;36(11):2036-41. Available from: http://www.ajnr.org/lookup/doi/10.3174/ajnr.A4430

14. Jenabi M, Peck KK, Young RJ, Brennan N, Holodny Al. Probabilistic fiber tracking of the language and motor white matter pathways of the supplementary motor area (SMA) in patients with brain tumors. J Neuroradiol [Internet]. 2014 Dec 1 [cited 2019 Sep 30];41(5):342-9. Available from: https://www.sciencedirect.com/science/article/pii/S0150986113001302

15. Li Z, Peck KK, Brennan NP, Jenabi M, Hsu M, Zhang Z, et al. Diffusion tensor tractography of the arcuate fasciculus in patients with brain tumors: Comparison between deterministic and probabilistic models. J Biomed Sci Eng [Internet]. 2013;6(2):192-200. Available from: https://www.ncbi.nlm.nih.gov/pubmed/25328583

16. Burkett DJ, Garst JR, Hill JP, Kam A, Anderson DE. Deterministic Tractography of the Descending Tract of the Spinal Trigeminal Nerve Using Diffusion Tensor Imaging. J Neuroimaging [Internet]. 2017 Sep;27(5):539-44. Available from: http://doi.wiley.com/10.1111/jon.12425

17. Anthofer JM, Steib K, Fellner C, Lange M, Brawanski A, Schlaier J. DTI-based deterministic fibre tracking of the medial forebrain bundle. Acta Neurochir (Wien) [Internet]. 2015 Mar 15;157(3):469-77. Available from: http://link.springer. com/10.1007/s00701-014-2335-y

18. Jbabdi S, Johansen-Berg H. Tractography: Where Do We Go from Here? Brain Connect [Internet]. 2011 Sep;1(3):169-83. Available from: http://www.liebertpub.com/doi/10.1089/brain.2011.0033

19. Schonberg T, Pianka P, Hendler T, Pasternak O, Assaf Y. Characterization of displaced white matter by brain tumors using combined DTI and fMRI. Neuroimage [Internet]. 2006 May;30(4):1100-11. Available from: https://linkinghub.elsevier. com/retrieve/pii/S1053811905024626

20. Witwer BP, Moftakhar R, Hasan KM, Deshmukh P, Haughton V, Field A, et al. Diffusion-tensor imaging of white matter tracts in patients with cerebral neoplasm. J Neurosurg [Internet]. 2002;97(3):568-75. Available from: https://thejns.org/ view/journals/j-neurosurg/97/3/article-p568.xml

21. Provenzale JM, Mukundan S, Barboriak DP. Diffusion-weighted and Perfusion MR Imaging for Brain Tumor Characterization and Assessment of Treatment Response. Radiology [Internet]. 2006;239(3):632-49. Available from: http://pubs. rsna.org/doi/10.1148/radiol.2393042031

22. Al-Okaili RN, Krejza J, Wang S, Woo JH, Melhem ER. Advanced MR Imaging Techniques in the Diagnosis of Intraaxial Brain Tumors in Adults. RadioGraphics [Internet]. 2006 Oct;26(suppl_1):S173-89. Available from: http://pubs.rsna.org/ doi/10.1148/rg.26si065513

23. Krakowiak M, Stoniewski P, Dzierżanowski J, Szmuda T. Future of the nerve fibres imaging: tractography application and development directions. Folia Morphol (Warsz) [Internet]. 2015 Sep 2;74(3):290-4. Available from: https://journals.viamedica.pl/folia morphologica/article/view/38825

24. Tracey D. Ascending and Descending Pathways in the Spinal Cord. In: The Rat Nervous System [Internet]. Elsevier; 2004. p. 149-64. Available from: https://linkinghub.elsevier.com/retrieve/pii/B9780125476386500080

25. Sterr A, Shan Shen, Szameitat AJ, Herron KA. The Role of Corticospinal Tract Damage in Chronic Motor Recovery and Neurorehabilitation: A Pilot Study. Neurorehabil Neural Repair [Internet]. 2010 Jun;24(5):413-9. Available from: http:// journals.sagepub.com/doi/10.1177/1545968309348310

26. Seo JP, Jang SH. Different Characteristics of the Corticospinal Tract According to the Cerebral Origin: DTI Study. Am J Neuroradiol [Internet]. 2013 Jul;34(7):1359-63. Available from: http://www.ajnr.org/lookup/doi/10.3174/ajnr.A3389 
27. Min Z, Niu C, Zhang Q, Zhang M, Qian Y. Optimal Factors of Diffusion Tensor Imaging Predicting Corticospinal Tract Injury in Patients with Brain Tumors. Korean J Radiol [Internet]. 2017;18(5):844. Available from: https://synapse.koreamed. org/DOlx.php?id=10.3348/kjr.2017.18.5.844

28. Morita N, Wang S, Kadakia P, Chawla S, Poptani H, Melhem ER. Diffusion Tensor Imaging of the Corticospinal Tract in Patients with Brain Neoplasms. Magn Reson Med Sci [Internet]. 2011;10(4):239-43. Available from: http://joi.jlc.jst.go.jp/ JST.JSTAGE $/ \mathrm{mrms} / 10.239$ ?from=CrossRef

29. Gao B, Shen X, Shiroishi MS, Pang M, Li Z, Yu B, et al. A pilot study of pre-operative motor dysfunction from gliomas in the region of corticospinal tract: Evaluation with diffusion tensor imaging. Fung SH, editor. PLoS One [Internet]. 2017 Aug 22;12(8):e0182795. Available from: https://dx.plos.org/10.1371/journal.pone.0182795

30. Weiss C, Tursunova I, Neuschmelting V, Lockau H, Nettekoven C, Oros-Peusquens A-M, et al. Improved nTMS- and DTI-derived CST tractography through anatomical ROI seeding on anterior pontine level compared to internal capsule. NeuroImage Clin [Internet]. 2015;7:424-37. Available from: https://linkinghub.elsevier.com/retrieve/pii/S2213158215000078

31. Maraka S, Jiang Q, Jafari-Khouzani K, Li L, Malik S, Hamidian H, et al. Degree of corticospinal tract damage correlates with motor function after stroke. Ann Clin Transl Neurol [Internet]. 2014;1(11):891-9. Available from: http://doi.wiley. com/10.1002/acn3.132

32. Geranmayeh F, Brownsett SLE, Wise RJS. Task-induced brain activity in aphasic stroke patients: what is driving recovery? Brain [Internet]. 2014 Oct;137(10):2632-48. Available from: https://academic.oup.com/brain/article-lookup/ doi/10.1093/brain/awu163

33. Fridriksson J, Guo D, Fillmore P, Holland A, Rorden C. Damage to the anterior arcuate fasciculus predicts non-fluent speech production in aphasia. Brain [Internet]. 2013 Nov;136(11):3451-60. Available from: https://academic.oup.com/ brain/article-lookup/doi/10.1093/brain/awt267

34. Fujii M, Maesawa S, Motomura K, Futamura M, Hayashi Y, Koba I, et al. Intraoperative subcortical mapping of a language-associated deep frontal tract connecting the superior frontal gyrus to Broca's area in the dominant hemisphere of patients with glioma. J Neurosurg [Internet]. 2015 Jun;122(6):1390-6. Available from: https://theins.org/view/journals/i-neurosurg/122/6/article-p1390.xml

35. De Witte E, Mariën P. The neurolinguistic approach to awake surgery reviewed. Clin Neurol Neurosurg [Internet] 2013;115(2):127-45. Available from: https://linkinghub.elsevier.com/retrieve/pii/S0303846712004933

36. Sitnikov AR, Grigoryan YA, Mishnyakova LP. Awake craniotomy without sedation in treatment of patients with lesional epilepsy. Surg Neurol Int [Internet]. 2018;9:177. Available from: http://www.ncbi.nlm.nih.gov/pubmed/30221022

37. Chernoff BL, Teghipco A, Garcea FE, Sims MH, Paul DA, Tivarus ME, et al. A Role for the Frontal Aslant Tract in Speech Planning: A Neurosurgical Case Study. J Cogn Neurosci [Internet]. 2018 May;30(5):752-69. Available from: https://www. mitpressjournals.org/doi/abs/10.1162/jocn a 01244

38. Catani M, Dell'Acqua F, Vergani F, Malik F, Hodge H, Roy P, et al. Short frontal lobe connections of the human brain. Cortex [Internet]. 2012 Feb;48(2):273-91. Available from: https://linkinghub.elsevier.com/retrieve/pii/S0010945211003170

39. Szmuda T, Rogowska M, Słoniewski P, Abuhaimed A, Szmuda M, Springer J, et al. Frontal aslant tract projections to the inferior frontal gyrus. Folia Morphol (Warsz) [Internet]. 2017 Dec 1;76(4):574-81. Available from: https://journals.viamedica.pl/folia morphologica/article/view/50306

40. Mandelli ML, Caverzasi E, Binney RJ, Henry ML, Lobach I, Block N, et al. Frontal White Matter Tracts Sustaining Speech Production in Primary Progressive Aphasia. J Neurosci [Internet]. 2014 Jul 16;34(29):9754-67. Available from: http:// www.jneurosci.org/cgi/doi/10.1523/JNEUROSCI.3464-13.2014

41. Sierpowska J, Gabarrós A, Fernandez-Coello A, Camins À, Castañer S, Juncadella M, et al. Morphological derivation overflow as a result of disruption of the left frontal aslant white matter tract. Brain Lang [Internet]. 2015 Mar;142:54-64. Available from: https://linkinghub.elsevier.com/retrieve/pii/S0093934X15000061

42. Kemerdere R, de Champfleur NM, Deverdun J, Cochereau J, Moritz-Gasser S, Herbet G, et al. Role of the left frontal aslant tract in stuttering: a brain stimulation and tractographic study. J Neurol [Internet]. 2016 Jan 11;263(1):157-67. Available from: http://link.springer.com/10.1007/s00415-015-7949-3

43. Andrea GD, Trillo G, Picotti V, Raco A. Trends in Reconstructive Neurosurgery [Internet]. Visocchi M, Mehdorn HM, Katayama Y, von Wild KRH, editors. Cham: Springer International Publishing; 2017. 241-250 p. (Acta Neurochirurgica Supplement; vol. 124). Available from: http://link.springer.com/10.1007/978-3-319-39546-3

44. Varriano F, Pascual-Diaz S, Prats-Galino A. When the FAT goes wide: Right extended Frontal Aslant Tract volume predicts performance on working memory tasks in healthy humans. He H, editor. PLoS One [Internet]. 2018 Aug 1;13(8):e0200786. Available from: https://dx.plos.org/10.1371/journal.pone.0200786

45. Essayed WI, Zhang F, Unadkat P, Cosgrove GR, Golby AJ, O'Donnell LJ. White matter tractography for neurosurgical planning: A topography-based review of the current state of the art. Neurolmage Clin [Internet]. 2017;15(January):659-72. Available from: https://linkinghub.elsevier.com/retrieve/pii/S2213158217301444

46. Abdullah KG, Lubelski D, Nucifora PGP, Brem S. Use of diffusion tensor imaging in glioma resection. Neurosurg Focus [Internet]. $2013 \mathrm{Apr} ; 34(4): E 1$. Available from: https://thejns.org/view/journals/neurosurg-focus/34/4/article-pE1.xml

47. Castellano A, Bello L, Michelozzi C, Gallucci M, Fava E, ladanza A, et al. Role of diffusion tensor magnetic resonance tractography in predicting the extent of resection in glioma surgery. Neuro Oncol [Internet]. 2012 Feb 1;14(2):192-202. Available from: https://academic.oup.com/neuro-oncology/article-lookup/doi/10.1093/neuonc/nor188

48. Zhukov VY, Goryaynov SA, Ogurtsova AA, Ageev IS, Protskiy S V, Pronin IN, et al. [Diffusion tensor imaging tractography and intraoperative neurophysiological monitoring in surgery of intracranial tumors located near the pyramidal tract]. Zh Vopr Neirokhir Im N N Burdenko [Internet]. 2016;80(1):5-18. Available from: https://www.researchgate.net/profile/Ivan Ageev/publication/301315444 Diffusion tensor imaging tractography and intraoperative neurophysiological monitoring in surgery of intracranial tumors located near the pyramidal tract/links/5873d42008ae8fce4924cc91.pdf 